ORIGINAL RESEARCH PAPER

\title{
COMPOSITIONAL AND MORPHOLOGICAL PROPERTIES OF PRETREATED ORANGE AND PLANTAIN PEELS: EFFECT ON APPLE JUICE CLARIFICATION EFFICACY OF POLYGALACTURONASE
}

\author{
OLAJIDE EMMANUEL ADEDEJI ${ }^{1 *}$, OLUFUNKE OLUSEYI EZEKIEL ${ }^{2}$ \\ ${ }^{I}$ Department of Food Science and Technology, Federal University Wukari, PMB 1020, Wukari, Nigeria, \\ ${ }^{2}$ Department of Food Technology, University of Ibadan, Ibadan, Nigeria \\ *Corresponding author: adedeji@fuwukari.edu.ng
}

Received on 24 June 2020

Revised on 9 October 2020

\begin{abstract}
This study evaluated the effect of alkaline and microwave pretreatments on the chemical composition and morphology of orange peel powder (OPP) and plantain peel powder (PPP), and the application of polygalacturonase, produced using the pretreated peels, in apple juice clarification. The pretreatment caused a significant $(\mathrm{p}<0.05)$ reduction in hemicelluloses and lignin, while pectin, cellulose, and the total sugar increased. The morphological evaluation showed disruption in the structures of OPP and PPP following their pretreatment with $\mathrm{NaOH}$ and microwave radiation. The most pronounced modification was recorded in the peels pretreated with the combined use of $\mathrm{NaOH}$ and microwave as compared to their separate use. Significantly higher $(p<0.05)$ titratable acidity, total solids, sugars, degree of lightness, and color intensity were recorded for the apple juice clarified with polygalacturonase produced using pretreated peel (PUEA) as compared to the one clarified with polygalacturonase produced using untreated peel (CREA). Also, PUEA was more preferred than CREA and compared significantly $(\mathrm{p}<0.05$ ) with the apple juice clarified with a commercial polygalacturonase in terms of colour, consistency, clarity, mouthfeel, and overall acceptability. This study showed that the pretreatment of OPP and PPP improved their chemical composition and morphology, and enhanced apple juice clarification efficacy of polygalacturonase.
\end{abstract}

Keywords: apple juice, clarification, peel, polygalacturonase, pretreatment

\section{Introduction}

Peels are the main by-products generated during the processing of fruits and vegetables, and account for $40-50 \%$ of their original weight (Castillo-Israel et al., 2015). These peels are considered suitable substrates for the production of microbial products (Salihu et al., 2015) and in recent times, their use has been drawing attention due to the high cost of traditional feedstocks (Wang et al., 2017).

https://doi.org/10.35219/foodtechnology.2020.2.04 
Agricultural residues such as orange, sweet lime, carrot, beetroot, plantain, lemon, and papaya peels are used as substrates for the production of pectinase enzymes due to their high pectin content (Wadhwa et al., 2015).

The use of orange and plantain peels as substrates for the production of bioproducts is increasing due to their availability ( $\mathrm{Li}$ et al., 2015). According to Statista (2018), approximately 23.5 million metric tons of orange fruit waste is generated annually in Nigeria. Ayanwale et al. (2016) also reported an annual waste generation of 6.5 million metric tons in the top plantain producing countries, such as Ghana, Nigeria, and Cote d'Ivoire, in West Africa. These peels are rich sources of nutrients that are essential for the proliferation of microorganisms used for production of bio-products (Romelle et al., 2016; Ayanwale et al., 2016).

Orange and plantain peels, like other agricultural residues, have a high lignocellulosic content. According to Zaslona and Trusek-Holownia (2015), orange peel on a dry basis contains $23.02 \%$ pectin, $37.08 \%$ cellulose, $11.04 \%$ hemicellulose, and $9.06 \%$ sugar. An analysis of plantain peel by Igbokwe et al. (2016) showed that it contains $46 \%$ cellulose and $25.7 \%$ lignin. The physicochemical properties of plant tissues, which are a function of their composition in terms of lignin, cellulose, and hemicellulose, determine their bioconversion rate (Wang et al., 2017). This implies that lignin, cellulose, and hemicelluloses are physical barriers that limit the microbial and enzymatic hydrolysis of biomasses (Wang et al., 2017). Therefore, the pretreatment of agricultural residues is required to enhance the proliferation of microorganisms, thereby increasing the bioconversion rate of agricultural residues, and improving the yield and activity of bio-products (Li et al., 2015). Pretreatment disrupts the highly organized lignin-carbohydrate composite of agricultural residues (Li et al., 2015). This results in lignin removal with an attendant increase in the surface area of carbohydrates amenable to hydrolysis (Ethaib et al., 2016). Many studies have shown an improvement in the activity of enzymes, e.g. cellulase, pectinase, and xylanase, consequent to the pretreatment of agricultural residues (Salihu et al., 2015; El-Shishtawy et al., 2015; Li et al., 2015). However, many of these studies did not investigate the effect of residue pretreatment on the properties of enzymes and their attendant behaviours in food systems. Our previous study (Adedeji and Ezekiel, 2019) reported an improvement in the stability, physicochemical and kinetic properties of polygalacturonase (PG) produced by Aspergillus awamori CICC 2040, consequent to alkaline and microwave pretreatment of orange and plantain peels. The objective of this study was to evaluate the effect of the pretreatment of orange and plantain on the efficacy of PG in apple juice clarification. The chemical composition and morphology of the peels as influenced by alkaline and microwave pretreatments were also investigated.

\section{Materials and methods}

\section{Materials}

Peels of orange (Citrus sinensis L. Osbeck) and plantain (Musa paradisiaca Linn.) were obtained from small-scale food processing factories in Ibadan, Nigeria. The 
fungal strain, Aspergillus awamori CICC (China Centre of Industrial Culture Collection) 2040 was obtained from China National Research Institute of Food and Fermentation, Beijing, China. The apple (Malus domestica Borkh) fruits (Green Trucape, South Africa) were obtained from Shoprite Supermarket, Ibadan, Nigeria. The polygalacturonase (17389-10G, Sigma, Switzerland) and polygalacturonic acid (Oxoid, England) were procured from Bristol Scientific Company Ltd., Lagos, Nigeria. The acetic acid, glycerol (Klincent Laboratory, India), n-hexane, methanol, sodium hydroxide (Loba Chemie, India), malt extract agar (MEA), glucose, sucrose, starch, isopropanol (ACROS Organics, USA), sodium acetate, and 3, 5 di-nitro salicylic acid (DNS) (Guangdong Guanghua, China) were procured from Ezek Robert Global Ltd., Ibadan, Nigeria. All the reagents used were of analytical grade.

\section{Production of orange and plantain peel powders}

The orange and plantain peels were blanched $\left(80^{\circ} \mathrm{C}\right.$ for $\left.3 \mathrm{~min}\right)$, rinsed, and dried in a hot air oven (NL9023A, Genlab Ltd., Cheshire, England) at $60{ }^{\circ} \mathrm{C}$ for $48 \mathrm{~h}$. The dried peels were milled into powders and sieved with the aid of a $0.8025 \mathrm{~mm}$ sieve (United States Pharmacopoeia Standard Sieves). The powders were packaged in polyethylene containers (ZipLock, China) and stored at $-20 \pm 2{ }^{\circ} \mathrm{C}$ in a freezer (Hisense, China) for subsequent analyses.

\section{Pretreatment of orange and plantain peel powders}

The orange and plantain peel powders were subjected to $\mathrm{NaOH}$ and MW separately and in combination $(\mathrm{NaOH}+\mathrm{MW})$, as reported in our earlier study (Adedeji and Ezekiel, 2019).

For $\mathrm{NaOH}$ pretreatment, the orange peel powder (OPP) and plantain peel powder (PPP) $(5 \mathrm{~g})$ were treated with $100 \mathrm{~mL} 0.1 \mathrm{M} \mathrm{NaOH}$ for $12 \mathrm{~h}$. The residues were recovered and rinsed with distilled water to remove the excess $\mathrm{NaOH}$. This was followed by drying in a hot air oven (NL9023A, Genlab Ltd., Cheshire, England) at $60{ }^{\circ} \mathrm{C}$ for $24 \mathrm{~h}$ and stored $\left(-20 \pm 2^{\circ} \mathrm{C}\right)$ for subsequent analyses.

Microwave pretreatment was performed by treating the peel powder solution $(5 \%$, w/v) in a laboratory microwave oven (NX-802, Nexus, Shanghai, China, having a $25 \mathrm{~L}$ capacity, $800 \mathrm{~W}$ power output, and frequency of $2450 \mathrm{MHz}$ ) at a microwave power of $720 \mathrm{~W}$ for 10 minutes. Thereafter, the residue was recovered and ovendried at $60{ }^{\circ} \mathrm{C}$ for $24 \mathrm{~h}$, and then stored $\left(-20 \pm 2{ }^{\circ} \mathrm{C}\right)$ for subsequent analyses.

Combined $(\mathrm{NaOH}+\mathrm{MW})$ pretreatment was carried out by treating orange and plantain peel powders $(5 \%$, w/v) with $0.1 \mathrm{M} \mathrm{NaOH}$ for $12 \mathrm{~h}$; the mixture was treated in a laboratory microwave oven (NX-802, Nexus, Shanghai, China, having a $25 \mathrm{~L}$ capacity, $800 \mathrm{~W}$ power output, and frequency of $2450 \mathrm{MHz}$ ) at a microwave power of $720 \mathrm{~W}$ for $10 \mathrm{~min}$. The residues were recovered and rinsed with distilled water to remove the excess $\mathrm{NaOH}$. This was followed by drying in a hot air oven (NL9023A, Genlab Ltd., Cheshire, England) at $60^{\circ} \mathrm{C}$ for $24 \mathrm{~h}$ and stored $(-20 \pm 2$ $\left.{ }^{\circ} \mathrm{C}\right)$ for subsequent analyses.

Untreated orange and plantain peels served as controls. 


\section{Polygalacturonase production}

The solid-state fermentation procedure described by Dey et al. (2014) was adopted for the production of polygalacturonase. Five grams of untreated and pretreated powders were mixed with $10 \mathrm{~mL}$ of Czapek-dox medium $\left(2.5 \mathrm{~g} / \mathrm{L} \mathrm{NaNO}_{3}, 1 \mathrm{~g} / \mathrm{L}\right.$ $\mathrm{KH}_{2} \mathrm{PO}_{4}, 0.5 \mathrm{~g} / \mathrm{L} \mathrm{KCl}$ and $0.5 \mathrm{~g} / \mathrm{L} \mathrm{MgSO} 4.2 \mathrm{H}_{2} \mathrm{O}$ ) at $\mathrm{pH} 4.0$ in the ratio $1: 2$ in a 250 $\mathrm{mL}$ Erlenmeyer flask, and autoclaved $\left(121^{\circ} \mathrm{C}, 15 \mathrm{psi}\right)$ for $15 \mathrm{~min}$. Subsequently, the substrate was inoculated with $10^{6}$ spores $/ \mathrm{mL}$ of the culture and incubated in an incubator (CLN115 Pol Eko Aparatura, Slaski, Poland) at $28{ }^{\circ} \mathrm{C}$ for 5 days. Then the fermented mass was suspended in distilled water to form a $50 \mathrm{~g} / \mathrm{L}$ suspension. The suspension was placed in an incubator (CLN115 Pol Eko Aparatura, Slaski, Poland) at $30^{\circ} \mathrm{C}$ for $1 \mathrm{~h}$ and centrifuged (K24IR, Centurion Scientific Ltd, Chichester, UK) at $2200 \times \mathrm{g}$ for $10 \mathrm{~min}$. The supernatant was separated by using a Whatman No. 1 filter. The enzyme was stored at $-20{ }^{\circ} \mathrm{C}$ for further tests. The polygalacturonase extracts produced were screened based on their activity. The polygalacturonase extracts produced using the untreated and pretreated PPP had higher activity and stability than those from OPP, therefore they were selected for further study.

\section{Evaluation of polygalacturonase in apple juice clarification}

The apple juice was prepared according to the methodology outlined by Joshi et al. (2011). Fresh apple fruits were washed with water, cut into cubes of $1 \mathrm{~cm}^{3}$, and blended in a blender (BLX750RD, Kenwood, Sheffield, UK) to a pulpy consistency. The pulp was sieved by a 200 mesh sieve $(0.075 \mathrm{~mm})$ to obtain a cloudy juice. Subsequently, $50 \mathrm{~mL}$ of juice was measured and poured into four separate beakers. Each of the juice beakers was treated with $1 \mathrm{~mL}$ of different 5 $\mathrm{U} / \mathrm{mL}$ PG solutions (obtained from a preliminary investigation). The polygalacturonase solutions were: PG produced using untreated PPP, PG produced using pretreated PPP, and a commercial PG. The control sample was prepared by replacing the PG solution with $1 \mathrm{~mL}$ distilled water. The prepared samples were incubated at $50{ }^{\circ} \mathrm{C}$ for $5 \mathrm{~h}$ at a rotating speed of $200 \mathrm{rpm}$. Subsequently, the juice samples were pasteurized $\left(85^{\circ} \mathrm{C}\right.$ for $\left.2 \mathrm{~min}\right)$ and rapidly cooled to room temperature $\left(28 \pm 2{ }^{\circ} \mathrm{C}\right)$, then stored at $4{ }^{\circ} \mathrm{C}$.

\section{Analyses}

The pectin and extractive contents of OPP and PPP were determined by the methods of Liu et al. (2017), while cellulose, hemicellulose, lignin, ash, moisture, and total sugar contents were determined according to the procedures described by Irfan et al. (2011).

The morphology of untreated and pretreated OPP and PPP was determined by means of a scanning electron micrograph (Phenom ProX, Thermo Fisher Scientific, Bedford, MA, USA). Before the analysis, the samples were dried in a hot air oven (NL9023A, Genlab Ltd., Cheshire, England) at $60{ }^{\circ} \mathrm{C}$ for $15 \mathrm{~min}$. Subsequently, gold sputter coatings $(10-100 \mathrm{~nm})$ were made on the samples and microscopic examination was conducted at $5 \mathrm{kV}$. Images were taken at 2900x magnification (Agu et al., 2017). 
To determine the structural changes in the peels, Fourier transform infrared spectroscopic (FTIR) analysis was conducted with the aid of a spectrometer (BX 80857, Perkin Elmer Spectrum, Massachusetts, USA) whose scan range, scan number, scan speed, and resolution were 4000-6000 $\mathrm{cm}^{-1}, 64,0.5 \mathrm{cms}^{-1}$, and $41 \mathrm{~cm}$ ${ }^{1}$, respectively. The sample $(3 \mathrm{mg})$ was mixed with $300 \mathrm{mg}$ spectroscopic grade $\mathrm{KBr}$ on a disc fixed by an agar mortar. Thereafter, the disc was taken to the equipment operated at $10 \mathrm{MPa}$ for $3 \mathrm{~min}$ and the spectra were displayed on a computer screen attached (Nomanbhay et al., 2013).

The percentage transmittance, soluble solids, $\mathrm{pH}$, reducing, and total sugar of the apple juice were determined based on the procedures reported by Cerreti et al. (2016), while the total titratable acidity (TTA) and specific gravity were determined according to the methods described by Diamante and Umemoto (2015).

$L^{*}$ (a measure of lightness), $a^{*}$ (a measure of redness), $b^{*}$ (a measure of yellowness), deltachrome $(\Delta \mathrm{C})$, colour intensity $(\Delta \mathrm{E})$, and the hue angle of apple juice were measured with the aid of a colorimeter (CR-300, Konica-Minolta, Tokyo, Japan).

The sensory evaluation of the apple juice was conducted using a 9-point hedonic scale described by Joshi et al. (2011). Fifty panellists were used. The panellists comprised $62 \%$ female and $38 \%$ male postgraduate students of the Department of Food Technology, University of Ibadan, Nigeria. The panellists assessed the samples for colour, flavour, consistency, clarity, mouthfeel, and overall acceptability. The samples were served at $8 \pm 2{ }^{\circ} \mathrm{C}$, and evaluated by panellists under white light in separate booths.

\section{Statistical analysis}

Descriptive statistics and one-way ANOVA were used for the determination of the mean and standard deviation, while the Duncan Multiple Range Test was used to separate the means. These were achieved using SPSS version 23 (Stat-Ease Inc., Massachusetts, USA).

\section{Results and discussion}

\section{Effect of pretreatment on the chemical composition of orange and plantain peel powders}

The chemical constituents of un-treated and pre-treated OPP and PPP are shown in Table 1. A significant increase $(\mathrm{p}<0.05)$ in pectin content was recorded for OPP pretreated with $\mathrm{NaOH}$, microwave, and $\mathrm{NaOH}+\mathrm{MW}$. This increase could be due to the reduction of lignin and hemicelluloses as a result of pretreatment. Significantly higher pectin $(\mathrm{p}<0.05)$ was obtained for OPP and PPP pretreated with $\mathrm{NaOH}+\mathrm{MW}$ as compared to the other methods. This could be due to a higher rate of lignin and hemicellulose reduction in the peels pretreated with $\mathrm{NaOH}+\mathrm{MW}$. Since pectin is one of the main inducers of the proliferation of pectinolytic organisms, its concentration in the pretreated peels could be directly proportional to the yield and/or activity of bio-products. Li et al. (2015) also reported a higher 
pectin content consequent to the pretreatment of orange peel with the combination of microwave and surfactant as compared to the use of microwave only.

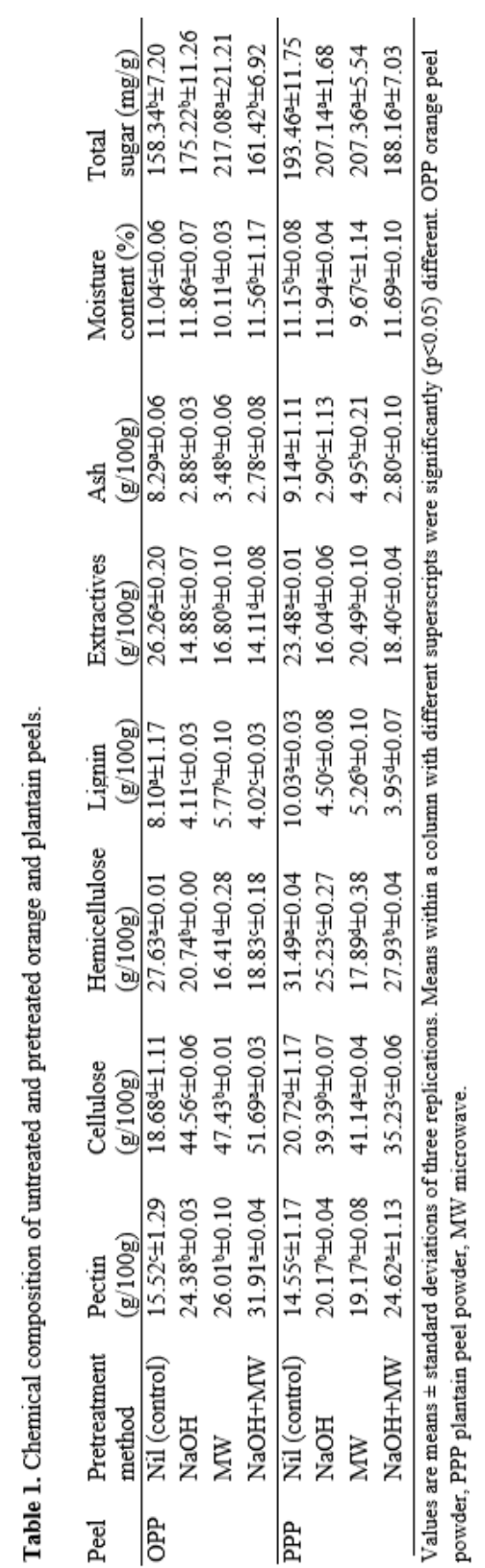

This increase could be attributed to cellulose bulging, a phenomenon that occurs as a result of cellulose condensation owing to lignin and hemicellulose removal (Pandey and Negi, 2015). The orange peel powder pretreated with $\mathrm{NaOH}+\mathrm{MW}$ exhibited the highest cellulose content of $51.69 \%$, while the microwave pretreated PPP had the highest cellulose content of $41.14 \%$. This variation suggested differences in the composition of orange and plantain peels, hence their varying susceptibility to the pretreatment methods. Cellulose comprises crystalline and amorphous fractions (Brodeur et al., 2011). While the former contributes to the crystallinity of cellulose and is resistant to breakdown, the latter is susceptible to breakdown through chemical, physical and biological means (Brodeur et al., 2011). Therefore, one of the objectives of pretreatment is to reduce the crystallinity of cellulose, which will invariably increase the amorphous fraction. The degree at which this occurs is a function of the pretreatment method, structural properties, and chemical composition of the substrate (Raj et al., 2016). Pretreatment caused a significant ( $\mathrm{p}$ $<0.05)$ reduction of hemicellulose contents of both OPP and PPP. This is consistent with the findings of Maeda et al. (2011) who also recorded a marked reduction of hemicelluloses in banana pseudostems subjected to chemical pretreatment. 
Substrates pretreated in a microwave showed the highest hemicellulose removal, i.e. a reduction from 27.63 to $16.41 \%$ in OPP, and 31.49 to $17.89 \%$ in PPP. Microwave pretreatment is known to be very efficient in the disintegration of hemicelluloses (Kumar et al., 2009). A remarkable decrease in the hemicellulose of wheat straws pretreated with microwave radiation was also reported by Kashaninejad et al. (2010).

Pretreatment caused a reduction in the lignin content of OPP and PPP. There was a significant difference $(\mathrm{p}<0.05)$ in the degree of lignin reduction by the pretreatment methods. Alkaline pretreatment was more efficient than the microwave for the removal of lignin in both substrates. The high solubilization potential of $\mathrm{NaOH}$ probably caused increased lignin removal in the peels (Ethaib et al., 2016). The lowest residual lignin content was recorded in the $\mathrm{NaOH}+\mathrm{MW}$ pretreated peels. This implied that $\mathrm{NaOH}+\mathrm{MW}$ pretreatment was the most efficient for lignin removal. Similar studies also showed that better lignin removal was achieved when microwave and $\mathrm{NaOH}$ were combined for the pretreatment of barley straw (Inan et al., 2016). In the presence of an alkali, microwave increases the degradation of lignin fibres through the dissolution of the phenolic hydroxyl group and the $\beta$-carbons that are adjacent to $\alpha$-carbonyl groups, which are the major building blocks of lignin (Starr et al., 2015).

Extractives reduced significantly $(\mathrm{p}<0.05)$ as a result of microwave and $\mathrm{NaOH}$ pretreatment. This agreed with the loss of extractives in timber mill sawdust (Trevorah and Othman, 2015). The loss of extractives was more intense in $\mathrm{NaOH}-$ pretreated OPP and PPP than in the microwave pretreated peels. This could be due to the higher dissolution efficiency of $\mathrm{NaOH}$. A higher reduction rate of extractives was found in bisulphite pretreated sugarcane bagasse as compared to the physical methods (Liu et al., 2017). Pretreatment also reduced the ash content of OPP and PPP. The reduction was most noticeable in the peels subjected to $\mathrm{NaOH}$-based pretreatments. This might have occurred during $\mathrm{NaOH}$ removal after pretreatment. According to $\mathrm{Yu}$ and Chan (2010), loss of ash often accompanies substrate washing after pretreatment. Since mineral elements contribute to the instability of $\mathrm{pH}$ in solutions, the low ash content of $\mathrm{NaOH}$ and $\mathrm{NaOH}+\mathrm{MW}$ pretreated peels will help improve $\mathrm{pH}$ stability during downstream processing (Liu et al., 2017).

For both OPP and PPP, the moisture content increased significantly $(\mathrm{p}<0.05)$ in $\mathrm{NaOH}$ and $\mathrm{NaOH}+\mathrm{MW}$ pretreated substrates: however, it decreased significantly $(\mathrm{p}<0.05)$ in microwave pretreated peels. This could be due to the drying effect of microwave radiation. Microwave radiation, a form of dielectric energy, has a high drying efficiency (Bejar et al., 2011). The total sugar increased significantly (p < 0.05 ) as a result of pretreatments. This could be due to the increased concentration of cellulose in the pretreated peels and its subsequent break down to sugar (ElShishtawy et al., 2015). Chang et al. (2017) also reported an increase in the total sugar of alkaline pretreated rice straw. The highest sugar content was recorded in microwave pretreated OPP and PPP. Conversely, Inan et al. (2016) reported that microwave pretreated barley straw had a lower total sugar content when compared to $\mathrm{NaOH}+\mathrm{MW}$ pretreated straw. 


\section{Effect of pretreatment on the morphology of orange and plantain peels}

The morphology of untreated and pretreated peels is shown in Figure 1.

a.

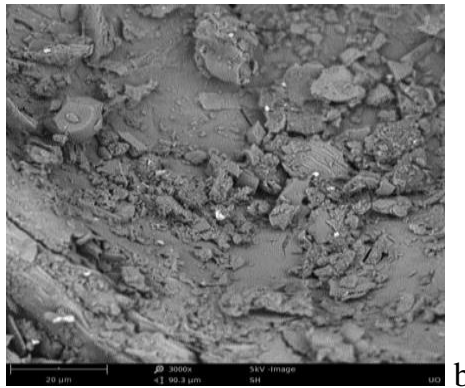

b.
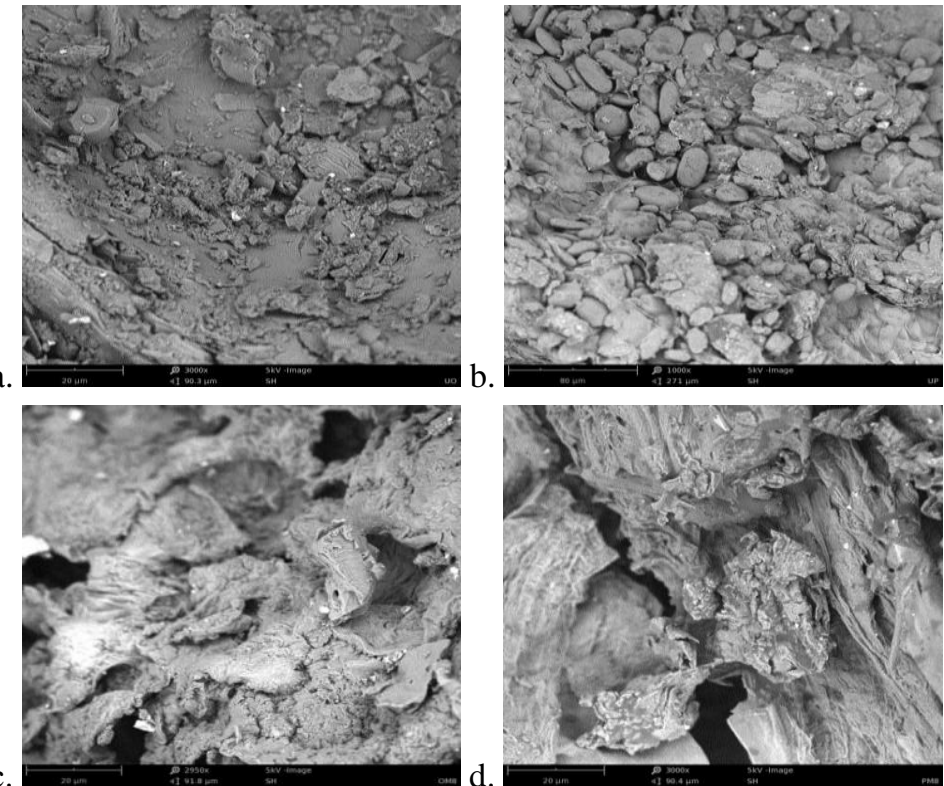

c.
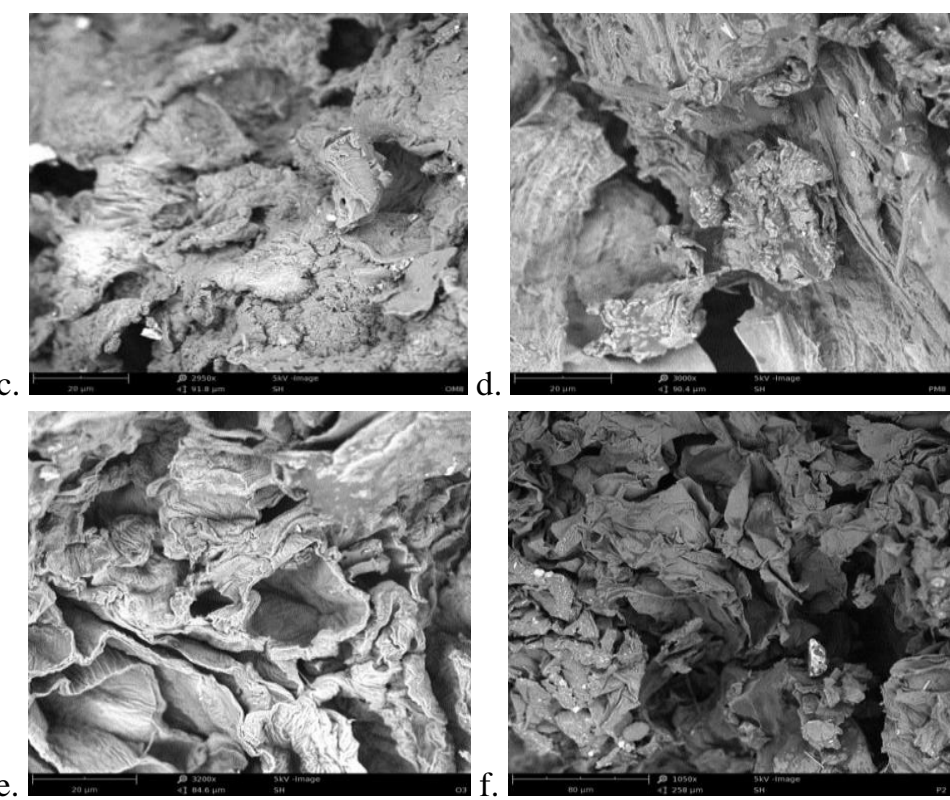

d. E
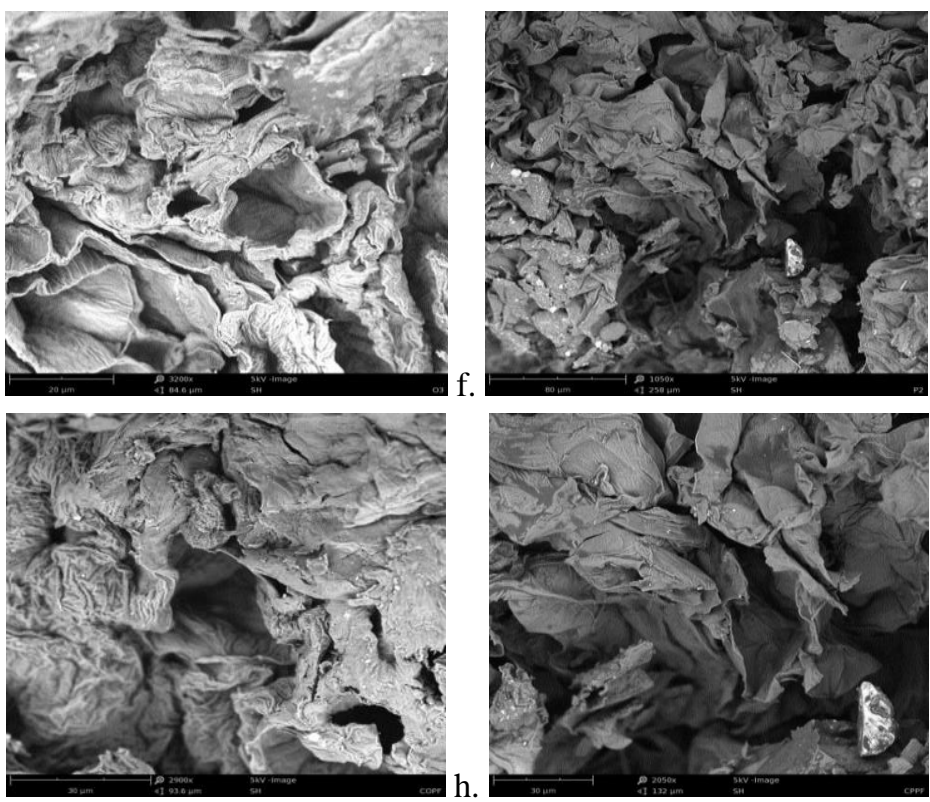

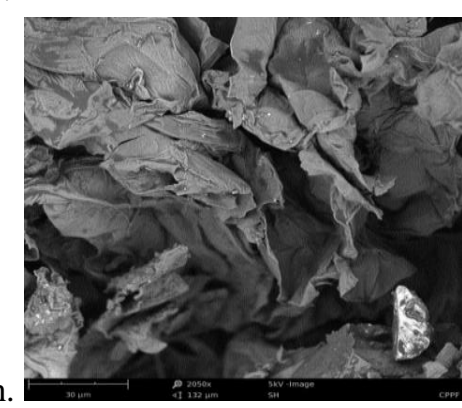

Figure 1. Morphology of untreated and pretreated orange and plantain peels: (a) untreated orange peel, (b) untreated plantain peel, (c) microwave-pretreated orange peel, (d) microwave-pretreated plantain peel, (e) $\mathrm{NaOH}$ - pretreated orange peel, (f) $\mathrm{NaOH}$ - pretreated plantain peel, (g) $\mathrm{NaOH}+$ microwave pretreated orange peel, (h) $\mathrm{NaOH}+$ microwave pretreated plantain peel.

The morphology of untreated OPP (Figure 1a) and PPP (Figure 1b) showed rigidity and proper alignment of structures of the peels. However, the pretreatment of OPP 
and PPP by microwave, $\mathrm{NaOH}$, and $\mathrm{NaOH}+\mathrm{MW}$ resulted in an increased surface area and porosity of surface structures. This is consistent with the findings of earlier studies, where pretreatment resulted in an increased porosity of feedstocks (Ethaib et al., 2016). One of the objectives of pretreatment is to reduce the rigid nature of residues, thereby allowing the increased proliferation of microorganisms and/or enzymes for improved metabolic activities. The microwave pretreated peels (Figure 1c and d) were characterized by pronounced porosity while the $\mathrm{NaOH}$ pretreated ones (Figure 1e and f) had severe surface roughness. The most severe disruption of microstructure was observed in the OPP and PPP subjected to $\mathrm{NaOH}+\mathrm{MW}$ pretreatment (Figure $1 \mathrm{~g}$ and $\mathrm{h}$ ). This suggested that the severity of surface deformation in the peels depended on the methods of pretreatment. During the pretreatment of rice straw for improved delignification, Chang et al. (2017) also found out that the structural properties of pretreated rice straw varied depending on the pretreatment method. The severe surface roughness of $\mathrm{NaOH}+\mathrm{MW}$ pretreated peels would give room for increased microbial proliferation and might cause an increase in the activity of bio-products. Sahare et al. (2012) attributed the increased saccharification of pretreated corn cob to rough external surface and expansion of lignin fibre.

\section{Effect of pretreatment on structures of orange and plantain peels}

The percentage of relative change in the intensity of different bands consequent to OPP pretreatment is shown in Table 2a. There was no visible band reduction at wavenumbers 2362, 2926, and $3423 \mathrm{~cm}^{-1}$, which were distinguished peaks for cellulose (Liu et al., 2017). This suggested a reduction in the asymmetric stretching of $\mathrm{CH}_{2} / \mathrm{CH}$ of alkane group and $\mathrm{O}-\mathrm{H}$ bending of the alcohol group of cellulose (Trevorah and Othman, 2015). This implied stability or increase in the cellulose content of the pretreated peels. The microwave pretreatment of OPP did not result in the reduction in peak with wavenumber $1728 \mathrm{~cm}^{-1}$, which was the hemicellulose band: however, a significant reduction to the tune of 5.84 and $6.02 \%$ in this peak was observed in the peel subjected to $\mathrm{NaOH}$ and $\mathrm{NaOH}+\mathrm{MW}$ pretreatment, respectively. The reduction was probably a result of the $\mathrm{C}=\mathrm{O}$ stretching of the aldehyde/ketone functional group (Trevorah and Othman, 2015). Significant reductions in the magnitude of 10.92 and $11.41 \%$ for $\mathrm{NaOH}$ and $\mathrm{NaOH}+\mathrm{MW}$ pretreated OPP, respectively were recorded for the wave number $1621 \mathrm{~cm}^{-1}$ owing to the $\mathrm{C}=\mathrm{C}$ stretching of alkene in the lignin side chains, which probably resulted in the disruption of linkages between carbohydrate and lignin (Wang et al., 2017). A higher percentage relative change in the intensity of the $\mathrm{NaOH}+\mathrm{MW}$ pretreated OPP is indicative of higher capacity of lignocellulosic-carbohydrate disruption. In the microwave and $\mathrm{NaOH}+\mathrm{MW}$ pretreated OPP, the intermolecular $-\mathrm{C}-\mathrm{H}$ bond of alkane in lignin side chains appeared to be disrupted (Liu et al., 2017) as a result of the reduction in absorption at $1436 \mathrm{~cm}^{-1}$; however, no significant change was observed in the OPP pretreated by microwave only. Peaks at the wavenumbers $1385,1276,1064$, and $770 \mathrm{~cm}^{-1}$ disappeared in the OPP pretreated with $\mathrm{NaOH}$ and $\mathrm{NaOH}+\mathrm{MW}$. 


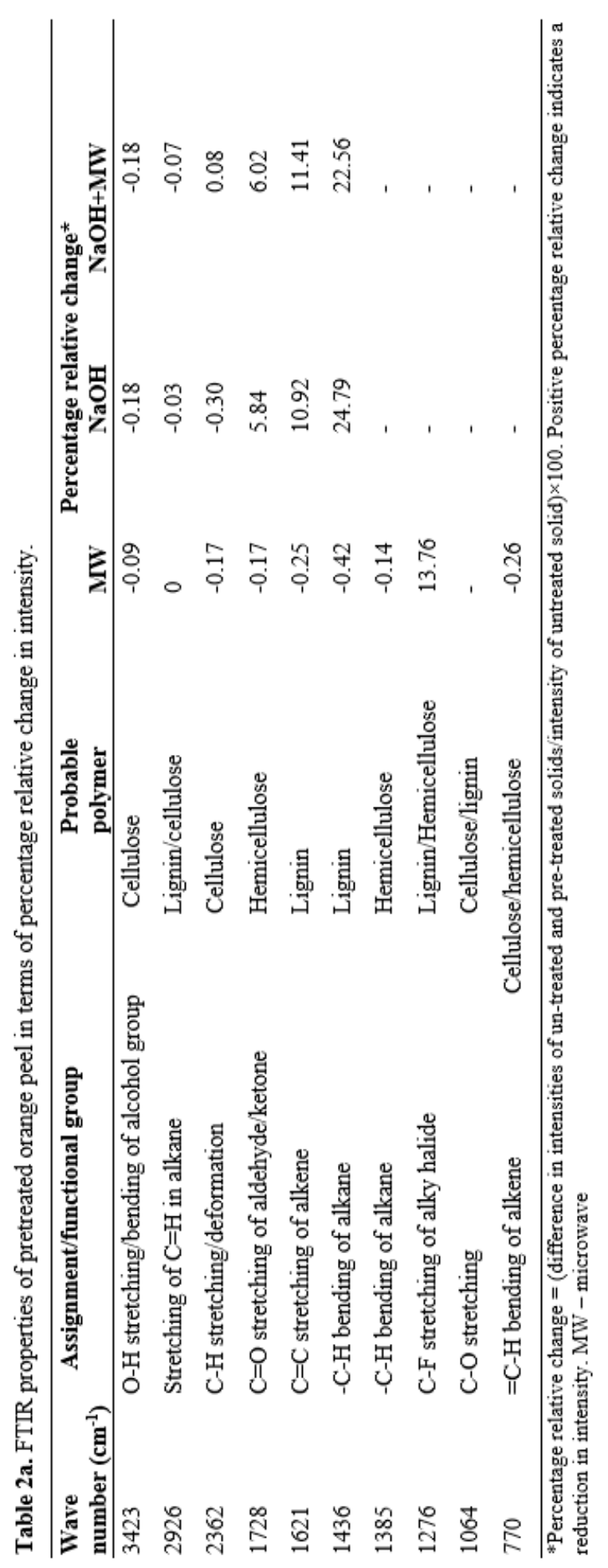




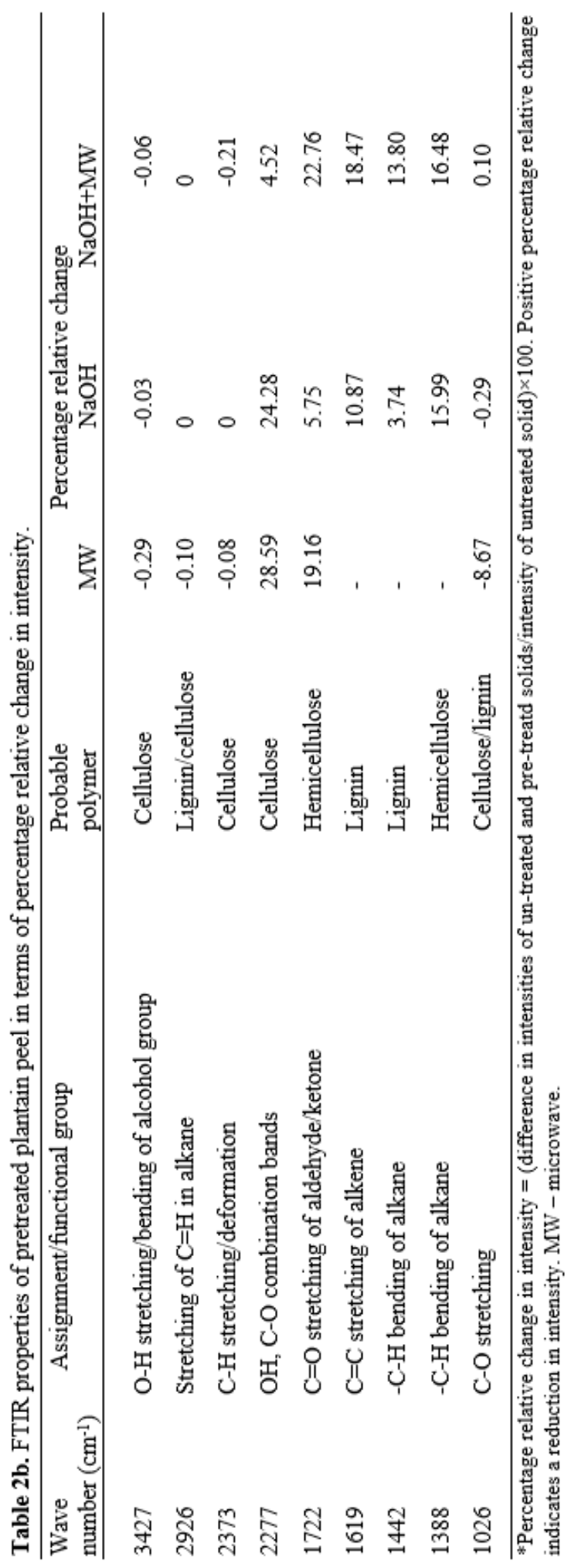


These peaks were related to the $-\mathrm{C}-\mathrm{H}$ bending of alkane, C-F stretching of alky halide, C-O stretching, and $=\mathrm{C}-\mathrm{H}$ bending of alkene, respectively, and their disappearance could be connected to the structural disruption of hemicellulose and lignin as a result of the pretreatment methods (Pandey and Negi, 2015).

The percentage relative change of the selected bands after PPP pretreatment is shown in Table 2b. An increase in the absorption peaks was recorded for pretreated PPP corresponding to the wavenumbers 3427,2926 , and $2373 \mathrm{~cm}^{-1}$. This could be due to a reduction in the asymmetric stretching of the $\mathrm{CH}_{2} / \mathrm{CH}$ of alkane group and the O-H bending of the alcohol group of cellulose (Trevoran and Othman, 2015). However, a significant reduction in absorption peaks was observed at wavenumbers 2277 and 1722 . These bands were the $\mathrm{OH}$ and $\mathrm{C}-\mathrm{O}$ combination bands (Santale and $\mathrm{Oh}, 2015$ ) and $\mathrm{C}=\mathrm{O}$ stretching of aldehyde/ketone (Trevoran and Othman, 2015), and are representative bands for cellulose and hemicelluloses, respectively. The reduction in these absorption peaks with the attendant increase in percentage relative change in intensity implied a significant reduction in hemicelluloses as a result of all the pretreatment methods. The degree of reduction in the absorption peak of pretreated PPP is of the order: $\mathrm{NaOH}+\mathrm{MW}<\mathrm{NaOH}<$ microwave and $\mathrm{NaOH}<$ microwave $<\mathrm{NaOH}+\mathrm{MW}$ at 2277 and $1722 \mathrm{~cm}^{-1}$, respectively. The highest percentage relative change in the intensity at absorption peaks 1619,1442 , and $1026 \mathrm{~cm}^{-1}$ which represented the $\mathrm{C}=\mathrm{C}$ stretching of alkene and the $-\mathrm{C}-\mathrm{H}$ bending of alkane of lignin-hemicellulose linkages (Wang et al., 2017) were recorded for PPP pretreated with $\mathrm{NaOH}+\mathrm{MW}$. This indicated that $\mathrm{NaOH}+\mathrm{MW}$ pretreatment was the most effective for lignin and hemicellulose removal.

\section{Chemical composition of apple juice}

The chemical composition of un-clarified apple juice (CTTA) and clarified apple juice samples are seen in Table 3. Enzymatic clarification caused a significant increase $(\mathrm{p}<0.05)$ in percentage transmittance. This implied an increase in juice clarity consequent to clarification. This could be due to the reduction of materials that would have contributed to cloudiness. According to Tribess and Tadini (2006), apple juice is cloudy due to the presence of pectin, cellulose, complex polysaccharides, proteins, tannins, and metals, therefore the clarification of the juice with enzymes, such as PG, is imperative. This causes the degradation of complex polysaccharides, especially pectin, which leads to crystal formation. The crystals are easily removed by centrifugation, decantation, and filtration (Sharma et al., 2014). Success was reported on the use of PG for the clarification of apple (Joshi et al., 2011) and guava (Kant et al., 2013) juices. Clarified samples differed significantly $(\mathrm{p}<0.05)$ in terms of clarity and soluble solids. The juice clarified with PG produced using untreated plantain peel (CREA) had the lowest value. There was no significant difference $(p>0.05)$ in terms of clarity and soluble solids between the juice clarified with commercial pectinase enzyme (CMEA) and the juice clarified with PG produced using pretreated plantain peel (PUEA). This showed that the pretreatment of plantain peel increased the efficiency of PG in apple juice clarification. This could be due to an increase in the affinity of PG for 
the substrate following an increased separation of protein molecules from the pectin that was present in the peel, which probably resulted in the high kinetic properties of the PG (Ucan et al., 2014). According to Abdel Wahab et al. (2018), enzyme reaction, protein folding, and interaction with substrates are dependent on their kinetic and thermodynamic properties. The more soluble solids exhibited by PUEA could be attributed to the higher degradation ability of the PG produced using the pretreated peel. This probably culminated in the production of sugars following the degradation of complex carbohydrates (Cerreti et al., 2016).

Table 3. Chemical composition of apple juice.

\begin{tabular}{|c|c|c|c|c|}
\hline & \multicolumn{4}{|c|}{ Apple juice } \\
\hline & CTTA & CREA & PUEA & CMEA \\
\hline$\% \mathrm{~T}_{650}$ & $13.89^{\mathrm{b}} \pm 0.57$ & $45.67^{\mathrm{ab}} \pm 0.51$ & $51.23^{\mathrm{a}} \pm 0.12$ & $52.41^{\mathrm{a}} \pm 0.27$ \\
\hline Soluble solids ( $\left.{ }^{\circ} \mathrm{Brix}\right)$ & $8.00^{\mathrm{b}} \pm 0.14$ & $8.67^{\mathrm{ab}} \pm 0.00$ & $9.20^{\mathrm{a}} \pm 0.28$ & $9.10^{\mathrm{a}} \pm 0.42$ \\
\hline pH & $3.57^{\mathrm{a}} \pm 0.00$ & $3.49^{\mathrm{ab}} \pm 0.00$ & $3.48^{\mathrm{c}} \pm 0.06$ & $3.51^{\mathrm{ab}} \pm 0.01$ \\
\hline TTA $(\%)$ & $0.06^{\mathrm{b}} \pm 0.01$ & $0.08^{\mathrm{ab}} \pm 0.03$ & $0.11^{\mathrm{a}} \pm 0.01$ & $0.09^{\mathrm{ab}} \pm 0.01$ \\
\hline $\begin{array}{c}\text { Reducing sugar }(\mathrm{mg} / 100 \\
\mathrm{mL})\end{array}$ & $18.26^{\mathrm{d}} \pm 0.78$ & $28.88^{\mathrm{c}} \pm 2.83$ & $45.18^{\mathrm{a}} \pm 1.44$ & $34.17^{\mathrm{b}} \pm 1.46$ \\
\hline Total sugar $(\mathrm{mg} / 100 \mathrm{~mL})$ & $36.12^{c} \pm 0.74$ & $50.31^{\mathrm{b}} \pm 0.04$ & $65.36^{\mathrm{a}} \pm 5.66$ & $53.52^{\mathrm{b}} \pm 11.72$ \\
\hline Vitamin C (mg/100 mL) & $0.84^{\mathrm{d}} \pm 0.04$ & $1.87^{\mathrm{b}} \pm 0.06$ & $2.08^{\mathrm{a}} \pm 0.00$ & $1.65^{\mathrm{c}} \pm 0.03$ \\
\hline Specific gravity & $1.14^{\mathrm{a}} \pm 0.01$ & $1.07^{\mathrm{b}} \pm 0.03$ & $1.08^{\mathrm{b}} \pm 0.00$ & $1.06^{\mathrm{b}} \pm 0.01$ \\
\hline
\end{tabular}

The data are means \pm standard deviations of triplicate scores. The means within a row with different superscripts were significantly different $(\mathrm{p}<0.05)$.

CTTA- un-clarified apple juice (control); CREA- apple juice clarified with polygalacturonase produced using untreated plantain peel; PUEA- apple juice clarified with polygalacturonase produced using pretreated plantain peel; CMEA- apple juice clarified with commercial polygalacturonase; $\% \mathrm{~T}_{650}$ - percentage transmittance at $650 \mathrm{~nm}$; TTA- titratable acidity.

Juice clarification caused a significant $\mathrm{pH}$ reduction $(\mathrm{p}<0.05)$, from 3.57 in CTTA to $3.49,3.48$, and 3.51 in CREA, PUEA, and CMEA, respectively. This could be due to the liberation of organic acid, which lowered the juice $\mathrm{pH}$. A previous study showed a reduction in the $\mathrm{pH}$ of juices consequent to enzymatic clarification (Joshi et al., 2011). A significantly lower $\mathrm{pH}(\mathrm{p}<0.05)$ was recorded for PUEA as compared to CREA and PUEA. This could be due to the modification of carbon and nitrogen after the pretreatment of the peel. This probably led to the production of PG with higher organic acid-producing potential. According to Han et al. (2015), enzymatic hydrolysis is often influenced by the carbon and nitrogen content of the substrate, as well as their ratio. The low $\mathrm{pH}$ of PUEA is advantageous because it could mean better shelf stability for the juice. While enzymatic clarification caused a significant $(\mathrm{p}<0.05)$ reduction in the $\mathrm{pH}$ of the apple juice, there was a corresponding significant $(\mathrm{p}<0.05)$ increase in the TTA. This might have also been a result of organic acid production. The highest TTA was recorded for PUEA and this corresponded to its lowest $\mathrm{pH}$ value.

There was a significant $(\mathrm{p}<0.05)$ increase in the reducing and total sugars of apple juice following enzymatic clarification. This could be due to the increased bioavailability of sugars consequent to the degradation of complex organic 
materials such as pectin and cellulose. This agreed with earlier reports where sugars increased after juice clarification (Sharoba and Ramadan, 2011; Bahramian et al., 2011). Among the clarified juice samples, PUEA had the highest $(\mathrm{p}<0.05)$ reducing and total sugar contents. This indicated the significance of the pretreatment of the PPP for the improvement of PG efficacy in apple juice clarification. Many studies (Irfan et al., 2011; Wang et al., 2017) reported a higher sugar yield as a result of the pretreatment of agricultural residues before enzymatic hydrolysis.

The vitamin $\mathrm{C}$ content of apple juice increased significantly $(\mathrm{p}<0.05)$ as a result of the enzymatic clarification, probably due to its bio-availability during the clarification operation. Khandare et al. (2011) also reported increased bioavailability of organic materials and phytochemicals during the enzymatic clarification of black carrot (Daucus carota). The PUEA had a significantly ( $\mathrm{p}<$ 0.05) higher vitamin $C$ content than CMEA and CREA. This implied higher ascorbic acid hydrolyzing potential of the PG produced from POPP, and this could be due to a higher affinity of the PG for the pectin in the juice. Significantly ( $p<$ 0.05 ) higher specific gravity was recorded for CTTA as compared to the clarified apple juice samples. This implied that clarification caused a significant reduction in the density of apple juice. This reduction could be due to the degradation of heavier polysaccharides to sugars, which are lighter (Diamante and Umemoto, 2015). There was no significant $(p>0.05)$ difference among the clarified juice samples in terms of specific gravity.

\section{Colour attributes of apple juice}

The colour attributes of apple juice as influenced by enzymatic clarification by PG enzyme are shown in Table 4.

Table 4. Colour attributes of apple juice.

\begin{tabular}{lrrrc}
\hline \multirow{2}{*}{ Color parameters } & \multicolumn{4}{c}{ Apple juice } \\
\cline { 2 - 5 } & \multicolumn{1}{c}{ CTTA } & \multicolumn{1}{c}{ CREA } & PUEA & \multicolumn{1}{c}{ CMEA } \\
\hline $\mathbf{L}^{*}$ & $35.48^{\mathrm{d}} \pm 0.04$ & $45.73^{\mathrm{c}} \pm 0.04$ & $50.96^{\mathrm{a}} \pm 0.02$ & $46.15^{\mathrm{b}} \pm 0.21$ \\
$\mathbf{a}^{*}$ & $3.31^{\mathrm{a}} \pm 0.03$ & $0.24^{\mathrm{b}} \pm 0.02$ & $-2.39^{\mathrm{d}} \pm 0.01$ & $-1.37^{\mathrm{c}} \pm 0.01$ \\
$\mathbf{b}^{*}$ & $13.91^{\mathrm{d}} \pm 0.03$ & $19.02^{\mathrm{b}} \pm 0.02$ & $19.17^{\mathrm{a}} \pm 0.01$ & $17.76^{\mathrm{c}} \pm 0.14$ \\
Hue angle & $76.63^{\mathrm{d}} \pm 0.08$ & $82.88^{\mathrm{c}} \pm 0.04$ & $89.29^{\mathrm{a}} \pm 0.07$ & $85.57^{\mathrm{b}} \pm 0.03$ \\
Chroma & $13.68^{\mathrm{c}} \pm 0.03$ & $18.30^{\mathrm{a}} \pm 0.02$ & $18.33^{\mathrm{a}} \pm 0.01$ & $17.00^{\mathrm{b}} \pm 0.15$ \\
Color intensity & $26.66^{\mathrm{d}} \pm 0.05$ & $37.89^{\mathrm{b}} \pm 0.04$ & $42.61^{\mathrm{a}^{\mathrm{a}} \pm 0.01}$ & $37.64^{\mathrm{c}} \pm 0.25$ \\
\hline
\end{tabular}

The data are means \pm standard deviations of triplicate scores. Means within a row with different superscripts were significantly different $(\mathrm{p}<0.05)$.

CTTA- un-clarified apple juice (control); CREA- apple juice clarified with polygalacturonase produced using untreated plantain peel; PUEA- apple juice clarified with polygalacturonase produced using pretreated plantain peel; CMEA- apple juice clarified with commercial polygalacturonase.

The $L^{*}$ value increased significantly $(\mathrm{p}<0.05)$ following the enzymatic clarification of apple juice. This validated the increase in percentage transmittance of the apple juice following the enzymatic clarification. This agreed with the increased $L^{*}$ of sapota juice following its clarification (Kaur and Sharma, 2013). 
The extent of increase in $L^{*}$ varied significantly $(\mathrm{p}<0.05)$ among the clarified samples, with PUEA having the highest value. The increase in the $L^{*}$ of PUEA could be an indication of increased clarity or degradation of colour compounds such as the auto-oxidation of phenols (Deshmukh et al., 2015). This further showed the efficacy of the pretreatment of the PPP in improving the efficacy of PG in juice clarification. The clarification of apple juice caused a significant $(p<0.05)$ decrease in $a^{*}$, while $b^{*}$ increased. These showed a reduction in the degree of redness and an increase in the degree of yellowness. Deviations from redness and increased yellowness were most prominent in PUEA. These might probably have occurred as a result of a higher concentration of carotenes in PUEA due to the increased potency of PG produced from pretreated PPP. The hue angle, deltachrome, and colour intensity also increased as a result of enzymatic clarification. The hue angle also varied significantly $(\mathrm{p}<0.05)$ among the samples. All the clarified samples had a hue angle between 80 and 90, and this also indicated the deviation of juice colour from red to yellow. The highest $(p<0.05)$ hue angle was recorded for PUEA and this implied that the most pronounced deviation occurred in this sample. There was no significant $(p>0.05)$ difference among PUEA and CREA in terms of Chroma; however, the highest $(\mathrm{p}<0.05)$ color intensity was recorded for PUEA. This implied a high colour purity in the sample. This is advantageous because it could increase the acceptability of the juice.

\section{Sensory properties of apple juice}

The effect of enzymatic clarification on the sensory properties of clarified juice is seen in Table 5.

Table 5. Sensory properties of apple juice as influenced by enzymatic clarification.

\begin{tabular}{lllll}
\hline & \multicolumn{4}{c}{ Apple juice } \\
\cline { 2 - 5 } & CTTA & CREA & PUEA & CMEA \\
\hline Color & $5.50^{\mathrm{b}} \pm 0.88$ & $5.86^{\mathrm{b}} \pm 1.03$ & $6.82^{\mathrm{a}} \pm 1.14$ & $6.86^{\mathrm{a}} \pm 0.88$ \\
Flavor & $6.56^{\mathrm{b}} \pm 0.86$ & $6.97^{\mathrm{a}} \pm 1.03$ & $7.02^{\mathrm{a}} \pm 1.00$ & $6.98^{\mathrm{a}} \pm 0.86$ \\
Consistency & $5.76^{\mathrm{c}} \pm 1.25$ & $6.12^{\mathrm{bc} \pm 1.02}$ & $6.86^{\mathrm{a}} \pm 1.20$ & $6.26^{\mathrm{b}} \pm 1.02$ \\
Clarity & $4.70^{\mathrm{c}} \pm 0.97$ & $6.18^{\mathrm{b}} \pm 1.14$ & $6.94^{\mathrm{a}} \pm 0.87$ & $7.00^{\mathrm{a}} \pm 0.97$ \\
Mouthfeel & $5.86^{\mathrm{c}} \pm 0.88$ & $5.92^{\mathrm{c}} \pm 1.16$ & $6.30^{\mathrm{b}} \pm 0.86$ & $6.94^{\mathrm{a}} \pm 0.88$ \\
Overall acceptability & $5.72^{\mathrm{c}} \pm 1.18$ & $6.28^{\mathrm{b}} \pm 0.99$ & $6.76^{\mathrm{a}} \pm 1.06$ & $6.36^{\mathrm{ab} \pm 1.18}$ \\
\hline
\end{tabular}

The data are means \pm standard deviations of fifty scores. Means within a row with different superscripts were significantly different $(\mathrm{p}<0.05)$.

CTTA- un-clarified apple juice (control); CREA- apple juice clarified with polygalacturonase produced using untreated plantain peel; PUEA- apple juice clarified with polygalacturonase produced using pretreated plantain peel; CMEA- apple juice clarified with commercial polygalacturonase.

Overall, there was a significant $(\mathrm{p}<0.05)$ improvement in all the sensory attributes investigated following the enzymatic clarification of apple juice. This supports earlier findings of improved sensory properties of orange juice as a result of enzymatic clarification (Joshi et al., 2011). There was no significant ( $\mathrm{p}>0.05$ ) difference between PUEA and CMEA in terms of colour and clarity. Besides, consumers tended to prefer PUEA as compared to CTTA and CREA in point of 
these parameters. There was no significant $(\mathrm{p}<0.05)$ difference in the degree of liking for all the clarified juices in terms of flavour; however, PUEA was the most preferred in terms of consistency and overall acceptability, while CMEA performed best in terms of mouthfeel. These findings clearly showed that PUEA performed better than CREA in regard to all the parameters studied. This indicated the better performance of PG as a result of the pretreatment of PPP. Several principles could be attributed to the improved sensory properties of PUEA as compared to CREA. The increased preference in terms of colour, consistency, clarity, and mouthfeel could be due to the higher rate of degradation and subsequent removal of colloidal pigments, especially polysaccharides (Sharoba and Ramadan, 2011). The increase in flavour could be due to increased bioavailability of sugars consequent to the breakdown of complex polysaccharides through the actions of PG (Deshmukh et al., 2015).

\section{Conclusions}

This study showed that alkaline and microwave pretreatments were effective for the compositional and morphological improvement of orange and plantain peels. Combined $\mathrm{NaOH}$ and microwave pretreatment was most efficient for the quality improvement of the peels as compared to the use of $\mathrm{NaOH}$ and microwave separately. The pretreatment of plantain peel improved the efficacy of polygalacturonase in apple juice clarification. There was an improvement in the chemical composition and colour attributes of apple juice following its clarification with PG produced using pretreated plantain peel. Besides, the apple juice clarified with this PG compared significantly with the juice clarified with commercial polygalacturonase in consumers' preference in terms of colour, flavour, consistency, and clarity.

\section{Acknowledgement}

This research was supported by the Tertiary Education Trust Fund of the Federal Republic of Nigeria (FUW/REG/S.39/vol.1/024).

\section{Conflict of interest}

The authors declare that they do not have any conflict of interest.

\section{References}

Abdel Wahab, W.A., Karam, E.A., Hassan, M.E., Kansoh, A.L., Esawya, M.A., Awad, G.E.A. 2018. Optimization of pectinase immobilization on grafted alginate-agar gel beads by 24 full factorial CCD and thermodynamic profiling for evaluating of operational covalent immobilization. International Journal of Biological Macromolecules, 113, 159-17.

Adedeji, O.E., Ezekiel, O.O. 2019. Pretreatment of selected peels for polygalacturonase production by Aspergillus awamori CICC 2040: Purification and application in mango juice extraction. Bioresource Technology Reports, 7, 100306. 
Agu, O.S., Tabil, L.G. Dumonceaux, T. 2017. Microwave-assisted alkali pre-treatment, densification and enzymatic saccharification of canola straw and oat hull. Bioengineering, 4, 25-32.

Ayanwale, A.B., Oluwole, F.A., Ojo, M., 2016. Innovation opportunities in plantain production inNigeria. Guide Book 1. Forum for Agricultural Research in Africa (FARA), Accra, Ghana.

Bahramian, S., Azin, M., Chamani, M. Gerami, A. 2011. Optimization of enzymatic extraction of sugars from kabkab date fruit. Middle-East Journal of Scientific Research, 7, 211-216.

Bejar, A.K., Echaou, K., Mihoubi, N.B. 2011. Effect of microwave treatment on physical and functional properties of orange (Citrus sinensis) peel and leaves. Food Science and Technology, 2, 1-7.

Brodeur, G., Yau, E., Badal, K., Collier, J., Ramachandran, K.B., Ramakrishnan, S. 2011. Chemical and physicochemical pretreatment of lignocellulosic biomass: A review. Enzyme Research, 787532.

Castillo-Israel, K.A.T., Baguio, S.F., Diasanta, M.D.B., Lizardo, R.C.M., Dizon, E.I., Mejico, M.I.F. 2015. Extraction and characterization of pectin from Saba banana [Musa 'saba' (Musa acuminata x Musa balbisiana)] peel wastes: A preliminary study. International Food Research Journal, 22, 190-195.

Cerreti, M., Liburdi, K., Benucci, I., Esti, M., 2016. The effect of pectinase and protease treatment on turbidity and on haze active molecules in pomegranate juice. LWT Food Science and Technology, 73, 326-333.

Chang, K.L., Chen, X.M., Wang, X.Q., Han, Y.J., Postprommanee, L., Liu, J.Y., Liao, Y.L., Ning, X.A., Sun, S.Y., Huang, Q., 2017. Impact of surfactant type for ionic liquid pretreatment on enhancing delignification of rice straw. Bioresource Technology, 227, 388-392.

Deshmukh, P.S., Manjunatha, S.S. Raju, P.S. 2015. Rheological behaviour of enzyme clarified sapota (Achras sapota L) juice at different concentration and temperatures. Journal of Food Science and Technology, 52, 1896-1910.

Dey, T.B., Adak, S., Bhattacharya, P., Banerjee, R., 2014. Purification of polygalacturonase from Aspergillus awamori Nakazawa MTCC 6652 and its application in apple juice clarification. LWT - Food Science and Technology, 59, 591-595.

Diamante, L., Umemoto, M., 2015. Rheological properties of fruits and vegetables: A review. International Journal of Food Properties, 18, 1191-1210.

El-Shishtawy, R.M., Mohamed, S.A., Asiri, A.M., Gomaa, A.M., Ibrahim, I.H., Al-Talhi, H.A., 2015. Saccharification and hydrolytic enzyme production of alkali pretreated wheat bran by Trichoderma virens under solid state fermentation. BMC Biotechnology, 15, 37-50.

Ethaib, S., Omar, R., Mazlina, M.K.S., Radiah, A.B.D., Syafiie, S., 2016. Microwaveassisted dilute acid pretreatment and enzymatic hydrolysis of sago palm bark. Bioresources, 11, 5687-5702.

Han, W., Lam, W.C., Melikoglu, M., Wong, M.T., Leung, H.T., Ng, C.L., Yan, P., Yeung, S.Y., Lin, C.S.K. 2015. Kinetic analysis of a crude enzyme extract produced via solid State fermentation of bakery waste. Sustainable Chemistry and Engineering, 3, 2043-2048. 
Igbokwe, P.K., Idogwu, C.N., Nwabanne, J.T., 2016. Enzymatic hydrolysis and fermentation of plantain peels: optimization and kinetic studies. Advances in Chemical Engineering and Science, 6, 216-235.

Inan, H., Turkay, O., Akkiris, C., 2016. Microwave and microwave-chemical pretreatment application for agricultural waste. Desalination and Water Treatment, 57, 2590-2596.

Irfan, M., Gulsher, M., Abbas, S., Syed, Q., Nadeem, M., Baig, S., 2011. Effect of various pretreatment conditions on enzymatic saccharification. Songklanakarin Journal of Science and Technology, 33, 397-404.

Joshi, V.K., Parmar, M., Rana, N., 2011. Purification and characterization of pectinase produced from apple pomace and evaluation of its efficiency in fruit juice extraction and clarification. Indian Journal of Natural Produts and Resources, 2, 189-197.

Kant, S., Vohra, A., Gupta, R., 2013. Purification and physicochemical properties of polygalacturonase from Aspergillus niger MTCC 3323. Protein Expression and Purification, 87, 11-16.

Kaur, M., Sharma, H.K., 2013. Effect of enzymatic treatment on carrot cell wall for increased juice yield and effect on physicochemical parameters. African Journal of Plant Science, 7, 234-243.

Kashaninejad, M., Kashaninejad, B. and Tabil, L.G. 2010. Effect of microwave pretreatment on densification of wheat straw. Annual International Meeting of the American Society of Agricultural and Biological Engineers. Pittsburgh, Pennsylvania.

Khandare, V., Walia, S., Singh, M., Kaur, C., 2011. Black carrot (Daucus carota ssp. Sativus) juice: Processing effects on antioxidant composition and color. Food Bioproduct Processing, 89, 482-486.

Kumar, P., Barrett, D.M., Delwiche, M.J. and Stroeve, P. 2009. Methods for pre-treatment of lignocellulosic biomass for efficient hydrolysis and biofuel production. Industrial Engineering Chemical Research, 48, 3713-3729.

Li, P., Xia, J., Shan, Y., Nie, Z., Wang, F., 2015. Effect of surfactant and microwaveassisted pretreatment on orange peel on extracellular enzymes production by Aspergillus japonicas PJ10. Applied Biochemistry and Biotechnology, 176, 758-771.

Liu, Z.J., Lan, T.Q., Lia, H., Gao, X., Zhang, H., 2017. Effect of bisulfite treatment on composition, structure, enzymatic hydrolysis and cellulase adsorption profiles of sugarcane bagasse. Bioresource Technology, 223, 27-33.

Maeda, R.N., Serpa, V.I., Rocha, V.A.L., Mesquita, R.A.A., Anna, L.M.M.S., de Castro, A.M., Driemeier, C.E., Pereira, N., Polikarpov, I., 2011. Enzymatic hydrolysis of pretreated sugar cane bagasse using Penicillium funiculosum and Trichoderma harzianum cellulases. Process Biochemistry, 46, 1196-1201.

Nomanbhay, S.M., Hussain, R., Palanisamy, K., 2013. Microwave-assisted alkaline pretreatment and microwave assisted enzymatic saccharification of oil palm empty fruit bunch fiber for enhanced fermentable sugar yield. Journal of Sustainable and Bioenergy Systems, 3, 7-17.

Pandey, A.K., Negi, S., 2015. Impact of surfactant assisted acid and alkali pretreatment on lignocellulosic structure of pine foliage and optimization of its saccharification parameters using response surface methodology. Bioresource Technology, 192, 115125.

Raj, T., Gaur, R., Dixit, P., Gupta, R. P., Kagdiyal, V., Kumar, R. and Deepak, K. 2016. Ionic liquid pretreatment of biomass for sugars production: driving factors with a 
plausible mechanism for higher enzymatic digestibility. Carbohydrate Polymers, 149, 369-381.

Romelle, F.D., Rani, A., Manohar, R.S. 2016. Chemical composition of some selected fruit peels. European Journal of Food Science and Technology, 4, 12-21.

Sahare, P., Singh, R., Laxman, R.S., Rao, M., 2012. Effect of alkali pretreatment on the structural properties and enzymatic hydrolysis of corn cob. Applied Biochemistry and Biotechnology, 168, 1806-1819.

Salihu, A., Abbas, O., Sallau, A.B., Alam, Z., 2015. Agricultural residues for cellulolytic enzyme production by Aspergillus niger: effect of pretreatment. 3 Biotech, 5, 11011106.

Santale, G.D., Oh, M., 2015. Improving alkaline pretreatment method for preparation of whole rice waste biomass feedstock and bioethanol production. RSC Advances, 5, 97171-97179.

Sharma, H.P., Patel, H., Sharma, S. 2014. Enzymatic extraction and clarification of juice from various fruits-A review. Trends in Postharvest Technology, 2, 1-14.

Sharoba, A.M., Ramadan, M.F. 2011. Rheological behaviour and physicochemical characteristics of Goldenberry (Physalis peruviana) juice as affected by enzymatic treatment. Journal of Food Processing and Preservation, 35, 201-219.

Starr, T., Harper, D.P. and Rials, T.G. 2015. The effects of electron beam irradiation dose on the mechanical performance of red maple (Acer rubrum). Bioresources, 10, 956969.

Statista, 2018. Orange production worldwide from 2012/2013 to 2017/2018. Retrieved from statista.com/statistics/577398/world-orange-production/ on 10 November, 2018 by $6: 32$ am.

Trevorah, R.M., Othman, M.Z., 2015. Alkali pretreatment and enzymatic hydrolysis of Australian timber mill sawdust for biofuel production. Journal of Renewable Energy, 284250 .

Tribess, T.B., Tadini, C.C., 2006. Inactivation kinetics of pectin methyesterase in orange juice as a function of $\mathrm{pH}$ and temperature-time process conditions. Journal of the Science of Food and Agriculture, 86, 1328-1335.

Ucan, F., Akyildiz, A., Agcam, E. 2014. Effects of different enzymes and concentrations in the production of clarified lemon juice. Journal of Food Processing, 215854.

Wadhwa, M., Bakshi, M.P.S., Makkar, H.P.S., 2015. Wastes to worth: value added products from fruit and vegetable wastes. CAB Reviews, 10, 43-68.

Wang, S., Lia, F., Zhang, P., Jin, S., Tao, X., Tanga, X., Wang, H., 2017. Ultrasound assisted alkaline pretreatment to enhance enzymatic saccharification of grass clipping. Energy Conversation and Management, 149, 409-415.

Yu, B. Chan,H. 2010. Effect of the ash on enzymatic hydrolysis of steam-exploded rice straw. Bioresource Technology, 101, 9114-9119.

Zaslona, H., Trusek-Holownia, A., 2015. Enhanced production of polygalacturonase in solid state fermentation: selection of process conditions, isolation and partial characterization of the enzyme. Acta ABP Biochemical Polonica, 62, 651-657. 